\title{
Talking Engineering: Students' Translanguaging in Engineering Education
}

\section{Mrs. Greses Perez, Stanford University}

Greses A. Pérez is a Ph.D. student in Curriculum Studies and Teacher Education with a focus on Science Education. Before coming to Stanford, Greses was a bilingual math and science educator at public elementary schools in Texas, where she served in the Gifted and Talented Advisory District Committee and the Elementary Curriculum Design team. As a science mentor at the Perot Museum, Greses locally supported the development of teachers by facilitating workshops and creating science classroom kits. She taught in bilingual, Montessori and university classrooms in Texas and in Dominican Republic, her birth country. She earned a B.S. in Civil Engineering from Santo Domingo Technological Institute (INTEC) and a M.Eng. in Environmental Engineering from the University of Puerto Rico at Mayagüez (UPRM) as well as a M.Ed. degree in School Leadership from Southern Methodist University (SMU). Her current research interests are located at the intersection of science and engineering education, multilingualism and emerging technologies. She is interested in the teaching and learning of engineering in the science classroom and the opportunities to create a language-rich environment for multilingual learners in this context. Prior to starting her career in education, Greses was a project manager for engineering projects and hydrologic and hydraulic studies. 


\title{
Talking Engineering: Students' translanguaging in engineering education
}

\begin{abstract}
With the integration of engineering education in the $\mathrm{K}-12^{\text {th }}$ classroom, students are expected to be competent in the practices of engineering design. From the body of students in the elementary and secondary education system, bilinguals and speakers of languages other than English are one of the fastest growing populations among school children. For them, language represents not only a powerful tool to communicate ideas, but also a critical factor to construct knowledge. In order to best meet the needs of those students, we need to understand the ways bilinguals use language in the context of engineering. This lecture addresses the linguistic patterns of Hispanic fluent functional bilinguals, students who communicate effectively in English and Spanish, in the context of engineering. It also explores the possible affordances embedded in the engineering practices for language learning. Preliminary results suggest the relevant role of language in engineering engagement and the prevalence of hegemonic views of language during the task.
\end{abstract}

Keywords: bilingual/bicultural; language; science education; engineering education; minorities in engineering

\section{Problem}

The demographics of our country are changing at a rapid pace. According to the last American Community Survey (ACS) from the Census Data (2015), 71.81\% of school age individuals, who are speakers of languages other than English, identified themselves 
as Spanish speakers. Soon, Hispanics and Latinx will become the largest minority in our nation. In this population, $60 \%$ of the households are considered by the system as Limited English Proficiency with low levels of college attainment (US Census, 2015). Yet, years of educational reform have no resulted in educational gains for students who are English learners. For instance, during the 2011 NAEP writing assessment, 99\% of eighth- and twelfth-grade students classified as English language learners (ELL) performed below the proficient level. However, despite the low levels of performance among those students in reading and writing, they reach better results in engineering and technology. During the 2014 Technology \& Engineering Literacy (TEL) assessment from NAEP, 73\% of the ELLs successfully demonstrated TEL-related skills on design choice based on knowing the relevant requirements. These results suggest that engineering may provide affordances for language learning.

With the implementation of the Next Generation of Science Standards (NGSS), engineering design becomes part of what students need to know and be able to do in the science classrooms. Educators now face the challenge of teaching their students about engineers' ways of doing and knowing, which brings the need for effective pedagogical approaches to address the language intensive practices of engineering tasks. In these contexts, language could be either the gatekeeper or the ultimate medium to open access (Fairclough, 1982) to engineering for culturally and linguistically diverse students.

Because of the recent addition of engineering in the $\mathrm{K}-12^{\text {th }}$ science standards, educators have limited knowledge about the role of multilingual practices in the context engineering pedagogy. Drawing on data collected through video recording of the engineering tasks in English, Spanish and translanguaging, this paper seeks to provide 
information about the intersection between language learning, science education and engineering. More specifically, the paper address the following research question:

RQ: What is the role of language when students engage in an engineering task with a monolingual, one language only, or a translanguaging approach to language, two or more languages?

\section{Theoretical framework}

Languages evolve and change over time and space. Being bilingual represents more than being able to speak in two or more linguist codes because the idea of named languages, such as English and Spanish, is a social and political construction. In the last two decades, societies have been exposed to cultural, linguistic, and social diversity resulting from globalization, producing language variations worldwide. Political boundaries of nation and state have not been enough to constraint these variations. Differences in language result from the contact between colonial legacies, local varieties and vernacular culture (Pennycook, 2007). In this context, bilingualism is a range of sociolinguistic practices connected to identity, power and historical context and not only the existence of two or more linguistic codes (Heller, 2007.) Therefore, being bilingual means to naturally engage in translanguaging, the faculty of moving fluidly across languages or using hybrids of different 'varieties' of languages (García \& Wei, 2015). Therefore, linguistically diverse students should have the opportunities to construct utterances with more competent speakers and participate in the communicative setting of science and engineering classes with their full linguistic repertoire.

Engineering provides affordances for students to use their full linguistic repertoire. 
The problem-based nature of Engineering education engage students in discourse about how to define and study the problems inherent in understanding the content. These affordances open the access to learning opportunities designed to enhance instead of simplify bilinguals' knowledge (van Lier \& Walqui, 2010). In the light of the NGSS implementation, teachers and students can take advantage of the interplay between representations and the language used to describe them. Both the visual representations common in the science and engineering field are crucial in bilinguals building their conceptual understanding of the content and refining their ability to talk about it (Quinn, Lee and Valdés, 2012).

\section{Design}

In order to answer the question, what is the role of language when students engage in an engineering task with a monolingual, one language only, or a translanguaging approach to language, two or more languages?, the study draws on data collected from 20 bilingual participants, ages 7 through 12 years old, who attended an engineering multilingual program for Hispanic/Latinx students at Stanford University in 2017. Students engaged in an engineering task with three linguistic contexts: (a) English only, (b) Spanish only, and (c) Translanguaging. They were encouraged by the teachers to communicate in the three language conditions with signs around the room, adults modeling the language usage and instructional materials in the target language.

This project adopted a simultaneous triangulation approach by taking multiple measures with limited interactions between the sources of data during the data collection stage (Morse, 1991). However, only a subset of the data with preliminary results is 
included in this paper. The sample size for the study was selected based on the literature on qualitative methods. Because the study analyzes a phenomenology directed toward discerning the essence of experiences, a sample of 20 students (Van Kaam, 1959; Morse, 1994; Sandelowski, 1995) allow the researcher to analyze of the phenomenon of fluent functional bilinguals in engineering.

\section{Analyses and Findings}

To explore the particularities in the instances of talk where students engage in engineering in different linguistic contexts, the data gathered in the videos was coded manually and using the qualitative research software NVivo ${ }$. The codebook resulted from a combination of a priori codes (Burke \& Christensen, 2008) based on the language and engineering literature and a set of open codes (Glaser \& Strauss, 1967) that derived from the analysis of the videos. The data was coded at the level of the 'idea unit' (Chi, 1997; Miles \& Huberman, 1994).

The video analysis suggests that participants perceived that (1) language influence their perceptions of the engineering task, (2) different linguistic resources serve different purposes during the lesson, (3) there are important nuances and complexities in translanguaging when doing engineering in science, and (4) students thought about translanguaging in hegemonic ways as shown in research by Martinez (2013). Specifically, students' answers suggests that as their age increases they become more aware of their changes in linguistic patterns during instances in which they engaged with their peers in team building activities or content related assignments. These patterns and students' linguistic repertoire served a specific purpose depending on the nature of the 
activity. Although many of the participants indicated that they were aware of language usage, on occasion they engaged in translanguaging unconsciously. Students' behaviors suggest a complex interaction between individual agency and the social forces that influence language use. Many of students described English as the language for technical terms, such as engineering and science. Students described Spanish as the language of feelings and teamwork. Conversely, translanguaging was often seen as a process to find better words to communicate ideas more effectively. The intention of this paper is to delve below the surface of the multilingual phenomenon in engineering settings by revealing the story of how students access engineering and science through language, and understand bilingual students' perceptions about language in engineering.

\section{Contributions}

Given the considerable size of the Hispanic and Latinx population in the US, this group represents an opportunity to develop our nation's human capital. The United States requires leadership that analyzes the advantages of investments in our heterogeneous population, which brings the richness of their language and culture. This human capital can support our economic and intellectual growth as a nation (Chubin, May \& Babco, 2005).

During this study, participants perceived contradictory messages in what society valued around language and knowledge. Students described being disciplined in schools both when speaking the 'incorrect language' - Spanish during science in English or English when science is being taught in Spanish- or being label as deficient if they mixed languages when engaging in science and engineering practices. However, within their 
communities or families, the students' responses suggest that translanguaging or Spanish is seen as the language to connect with their communities. All the participants in this study either negate their use of translanguaging during the lesson or categorized it as 'incorrect language' for science learning in engineering education. In light of this results, educators need to bring into the classroom culturally sustaining pedagogy based on the world we live in and the students' knowledge and interest (Paris, 2012), which includes their full linguistic repertoire.

\section{Literature Cited}

Bureau of Labor Statistics (December, 2015). Architecture and Engineering Occupations. Retrieve from https://www.bls.gov/ooh/architecture-and-engineering/home.htm

Chubin, D. E., May, G. S., \& Babco, E. L. (2005). Diversifying the engineering workforce. Journal of Engineering Education, 94(1), 73-86.

Coy, P. and Lu, W. (2015) The Bloomberg Innovation Index. Retrieve from https://www.bloomberg.com/graphics/2015-innovative-countries/

Fairclough, N. (1982). BolingerDwight, Language - the loaded weapon: The use and abuse of language today. London and New York: Longman, 1980. Pp. $x+214$. Language in Society, 11(1), 110-120. doi:10.1017/S0047404500009064

García, O., \& Wei, L. (2015). Translanguaging, bilingualism, and bilingual education. The handbook of bilingual and multilingual education, 223-240.

Heller, M. (2007). Bilingualism as ideology and practice. In M. Heller (Ed.), Bilingualism: a social approach (pp. 1-22). New York: Palgrave.

Martínez, R. A. (2013). Reading the world in Spanglish: Hybrid language practices and 
ideological contestation in a sixth-grade English language arts classroom. Linguistics and Education, 24(3), 276-288.

Paris, D. (2012). Culturally sustaining pedagogy: A needed change in stance, terminology, and practice. Educational Researcher, 41(3), 93-97.

Pennycook, A. (2007). The myth of English as an international language. Disinventing and reconstituting languages, 90-115.

U.S. Census Bureau (2015). Community Survey (ACS) from the Census Data (2015).

Teddlie, C., \& Tashakkori, A. (2009). Foundations of mixed methods research: Integrating quantitative and qualitative approaches in the social and behavioral sciences. Sage.

Sandelowski, M. (1995). Sample size in qualitative research. Research in nursing \& health, 18(2), 179-183.

Walqui, A., \& Van Lier, L. (2010). Scaffolding the academic success of adolescent English language learners: A pedagogy of promise (pp. 1-41). San Francisco, CA: WestEd 